\title{
DIETARY PREPARATION AND PER CENT FAT MEASUREMENT BY HYDROSTATIC WEIGHING
}

\author{
T. R. THOMAS, L. D. CROUGH and J. ARAUJO
}

Exercise Physiology Laboratory, University of Missouri and Exercise Physiology Laboratory, University of Kansas, USA

\section{ABSTRACT}

To examine if the dietary preparation for hydrostatic weighing (HW) alters the \% fat measurement, seven men and three women (age $29 \pm 6$, Males $11.7 \pm 7.3 \%$ fat and Females $24.1 \pm 5.4 \%$ fat, mean \pm SD) were assessed before and after three meals. On separate days and in random order, each subject (1) ate a salad with toppings (600 g) with small beverage, (2) ate two bean burritos and one bean tostada $(900 \mathrm{~g})$ with small beverage, and (3) drank $800 \mathrm{ml}$ of carbonated beverage. The subject was reweighted $45 \mathrm{~min}$ after the meals and immediately after the beverage ingestion. Functional residual capacity was assessed simultaneously with underwater weight. Dependent t-tests indicated that body weight in air increased after each of the three means (Bean 0.78, Salad 0.92, Beverage $0.90 \mathrm{~kg}$, all $\mathrm{p}<0.05$ ), but underwater weights were unchanged. Following the salad, body density (1064.6 vs $\left.1061.8 \mathrm{~kg} . \mathrm{m}^{-3}\right)$ and $\%$ fat $(15.0 \mathrm{vs} 16.3 \%, \mathrm{p}<0.05)$ were significantly different pre-meal vs post-meal. Likewise, beverage ingestion resulted in decreased body density (1064.7 vs $\left.1061.2 \mathrm{~kg} . \mathrm{m}^{-3}\right)$ and increased $\%$ fat $(15.0$ vs $16.5 \%, p<0.05)$. The bean meal did not cause a change in measured body density (1062.8 vs 1062.8 $\left.\mathrm{kg} . \mathrm{m}^{-3}\right)$ or \% fat (15.8 vs $\left.15.8 \%\right)$. These results indicate that for the most accurate analysis, preliminary dietary preparation for $\mathrm{HW}$ should include food and beverage restriction.

Key words: Hydrostatic weighing, Per cent body fat, Body composition, Gastro-intestinal gas

\section{INTRODUCTION}

Hydrostatic weighing has been accepted as one of the best indirect methods of assessing per cent body fat in humans. The accuracy and reliability of this procedure depend in part on the normalisation of body weight and gastro-intestinal gas at the time of the assessment. Food or fluid intake may affect the $\mathrm{HW} \%$ fat measurement by increasing body weight, and/or increasing intestinal gas. The most serious effect would seem to be caused by gas-producing foods which could increase gastro-intestial gas to $500 \mathrm{ml}$ instead of the post absorptive $0-100 \mathrm{ml}$ (Bedell et al, 1956; Levitt and Bond, 1970).

Only Durnin and Satwanti (1982) have systematically examined the role of dietary preparation on the accuracy of hydrostatic weighing. Their results suggest that variations in preparatory protocol have only minimal influence on percentage body fat as determined by hydrostatic weighing. However, the type of food eaten was not specified. This apparent insignificance of dietary preparation for HW seems to warrant corroboration. Therefore, the purpose of the present study was to examine the effect of food or beverage intake on the assessment of percentage body fat by hydrostatic weighing.

\section{METHODS}

Ten adults, seven men and three women (Table I), gave informed consent to participate in this study. Each individual was comfortable in water and had previously been weighed underwater.

The hydrostatic weighing protocol has been previously described in detail (Thomas and Etheridge, 1980). Subjects were weighed in air (WA) on a Toledo platform scale with digital indicator (accurate to $50 \mathrm{~g}$ ), and weighed in water (WW) using a Chatillon autopsy scale (accurate to $25 \mathrm{~g}$ ). Initially, the subject performed two maximal vital capacity

Address for correspondence:

T. R. Thomas, PhD

Dept. of Health and Physical Education

101 Rothwell Gym

University of Missouri

Columbia, MO 65211

USA
TABLE I

Subject characteristics

\begin{tabular}{lcccr}
\hline Group & $\mathbf{n}$ & $\begin{array}{c}\text { Age } \\
\text { (year) }\end{array}$ & $\begin{array}{c}\text { Weight } \\
(\mathbf{k g})\end{array}$ & $\begin{array}{c}\text { Body Fat } \\
(\%)\end{array}$ \\
\hline Men & 7 & 28 & 77.91 & 11.7 \\
Women & 3 & 29 & 61.18 & 7.3 \\
& & 3 & 9.51 & 24.1 \\
Total & 10 & 29 & 72.89 & 5.4 \\
& & 6 & 12.74 & 15.4 \\
& & & & 8.8 \\
\hline
\end{tabular}

Values are means $\pm S D$

manoeuvres to open trapped alveolar air to the helium (Robertson, Engle and Bradley, 1978). Functional residual capacity (FRC) was measured by helium dilution simultaneously with the underwater weight measurement. In each case, three to five trials were performed to determine underwater weight. The HW procedure was identical for pre- and post-tests for each dietary treatment.

Each subject underwent three dietary treatments in random order, separated by 24 to 72 hours, but at the same time of day. The treatments consisted of (1) ingesting two bean burritos, one bean tostada, and $355 \mathrm{ml}(12 \mathrm{oz})$ of carbonated beverage (Bean). (2) ingesting a salad with multiple toppings gathered from a salad bar plus $355 \mathrm{ml}$ of carbonated beverage (Salad). (3) drinking $800 \mathrm{ml}$ (27 oz) of carbonated beverage (Drink). The average weights of these meals were $900 \mathrm{~g}, 600 \mathrm{~g}$ and $800 \mathrm{~g}$, respectively.

Prior to each dietary treatment, each subject (1) fasted for five hours (2) avoided gas-producing foods and gum for 24 hours (3) avoided liquid for one hour (4) avoided vigorous exercise for five hours (5) attempted to evacuate bowel and bladder just prior to testing.

HW was performed before each treatment, and again $45 \mathrm{~min}$ following the Bean or Salad meals, and immediately after the Drink. This timing was selected based on reports of the greatest rate of gas production occurring within the first hour after ingestion (Levitt and Bond, 1970). Immediately following each HW test, each subject rated the difficulty of 
the procedure according to a modified Borg Scale (Timson and Coffman, 1984). Possible ratings of perceived exertion (RPE) ranged from "no difficulty" (0) to "very, very hard" (10).

Dependent t-tests were used to analyse differences in pre- and post-tests for each treatment. Analysis of differences among treatments was not performed.

\section{RESULTS}

The reliability of hydrostatic weighing technique has been established previously using 40 subjects: $r=0.99$, mean absolute difference $(\bar{A}$ diff $)=1.6 \mathrm{~kg} \cdot \mathrm{m}^{-3}$ and $0.6 \%$ fat (Thomas and Etheridge, 1980). Reliability established for the present study $(N=14)$ was $r=0.99$ and $\bar{A}$ diff $=0.9$ kg. $\mathrm{m}^{-3}$ and $0.4 \%$ fat.

The results obtained by hydrostatic weighing before and after the dietary treatments are presented in Table II. Dependent t-tests indicated that WA was increased by all three treatments ( $p<0.05$ ). WW was not significantly altered by any of the dietary treatments. Body volume was increased in all conditions $(p<0.05)$, but body density was decreased only in the Salad $\left(-2.8 \mathrm{~kg} \cdot \mathrm{m}^{-3}, \mathrm{t}(9)=-2.29\right.$, $p<0.05)$ and Drink $(-3.5, t(9)-5.59, p<0.05)$ but not in the Bean treatment $\mathrm{t}(9)=0.15, \mathrm{p}>0.05)$. Per cent fat was increased significantly by 1.3 and $1.5 \%$ fat for the Salad and Drink conditions, respectively, but this measurement was not altered by the Bean meal (Fig. 1). Ratings of perceived exertion were increased significantly by the heavier Bean and Drink meals but not following the Salad ingestion (Table II).

TABLE ||

Hydrostatic weighing values before and after food or beverage intake

\begin{tabular}{|c|c|c|c|c|c|c|}
\hline \multirow[t]{2}{*}{ Treatment } & \multicolumn{6}{|c|}{ Variable } \\
\hline & $\begin{array}{l}\text { Lung } \\
\text { Volume } \\
\text { FRC (I) }\end{array}$ & $\begin{array}{c}\text { Air } \\
\text { Weight } \\
\text { (kg) }\end{array}$ & $\begin{array}{c}\text { Water } \\
\text { Weight } \\
\text { (kg) }\end{array}$ & $\begin{array}{c}\text { Body } \\
\text { Volume } \\
\text { (I) }\end{array}$ & 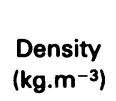 & RPE \\
\hline \multicolumn{7}{|l|}{ Bean } \\
\hline \multirow[t]{2}{*}{ Pre } & 2.452 & 72.91 & 2.186 & 68.610 & 1062.8 & 1.2 \\
\hline & 0.396 & 13.14 & 1.187 & 12.623 & 19.2 & 0.8 \\
\hline \multirow[t]{2}{*}{ Post } & 2.461 & $73.69^{*}$ & 2.223 & $69.337^{*}$ & 1062.8 & $1.9^{*}$ \\
\hline & 0.448 & 13.21 & 1.201 & 12.552 & 20.5 & 0.9 \\
\hline \multicolumn{7}{|l|}{ Salad } \\
\hline \multirow[t]{2}{*}{ Pre } & 2.419 & 72.83 & 2.296 & 68.410 & 1064.6 & 1.6 \\
\hline & 0.441 & 12.37 & 1.134 & 11.752 & 21.1 & 0.9 \\
\hline \multirow[t]{2}{*}{ Post } & 2.270 & $73.75^{*}$ & 2.326 & $69.458^{*}$ & $1061.8^{*}$ & 1.8 \\
\hline & 0.299 & 12.30 & 1.215 & 11.621 & 18.9 & 0.9 \\
\hline \multicolumn{7}{|l|}{ Drink } \\
\hline \multirow[t]{2}{*}{ Pre } & 2.496 & 72.93 & 2.249 & 68.498 & 1064.7 & 1.4 \\
\hline & 0.441 & 12.77 & 1.179 & 12.192 & 19.5 & 1.0 \\
\hline \multirow[t]{2}{*}{ Post } & 2.367 & $73.83^{*}$ & 2.200 & $69.572^{*}$ & $1061.2^{*}$ & $2.0^{*}$ \\
\hline & 0.447 & 12.77 & 1.208 & 12.210 & 19.4 & 0.7 \\
\hline
\end{tabular}

${ }^{*} p<0.05$, pre vs post. Values are means $\pm S D$

\section{DISCUSSION}

The reliability of hydrostatic weighing probably depends on the lung volume measurement, and test-retest results are improved when the air in the lungs is assessed with the subject submerged (Durnin and Taylor, 1960; Thomas and Etheridge, 1980). In the present study, any pre- vs post-test value greater than the test-retest $\bar{A}$ diff of $0.4 \%$ body fat can be ascribed directly to the treatment. The percentage body

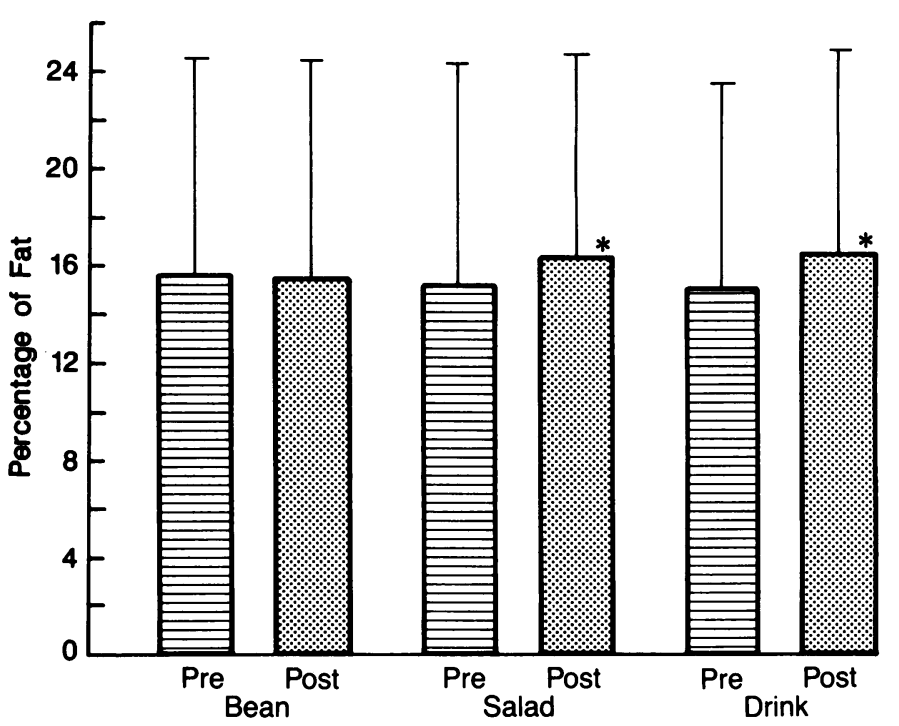

Fig. 1: Per cent body fat before and after the dietary treatments. Bars are means and lines are SD. ${ }^{*}$ pre vs post difference, $p<0.05$.

fat of each subject increased after drinking the carbonated beverage, and nine of the 10 subjects increased by more than $0.4 \%$. The Salad meal caused six of ten subjects to increase more than $0.4 \%$ fat with two gaining $\simeq 3 \%$ fat. The Bean meal surprisingly produced variable results since percentage body fat was reduced for four subjects and increased for 6 subjects, following this meal. Thus, only certain meals ingested prior to weighing apparently produce effects greater than the measurement error. Likewise, Girandola et al (1977) and Thomas et al (1979) observed that hydration levels can cause individual discrepancies as large as $2-3 \%$ fat determined by hydrostatic weighing. Variability of this magnitude could confound body composition research, especially in routine exercise training studies in which changes in percentage body fat average only 0-2\% (Wilmore et al, 1980).

Durnin and Satwanti (1982) reported that values for body fat increased an average of only $0.6 \%$ fat following an undescribed light meal of $2.09 \mathrm{MJ}$, a heavier meal (5.02-9.21 MJ), or an $800 \mathrm{ml}$ carbonated drink. The large SD's of their changes indicate some individuals had substantial alterations in the percentage body fat measurement. Average increases for the Salad and Drink (1.3 and $1.5 \%$ fat, respectively) in the present study were greater than those reported by Durnin and Satwanti (1982). The reason for our greater changes is unclear, but could relate to the $\mathrm{HW}$ procedures employed. In the present study, lung volume (FRC) was measured simultaneously with the WW while the subject was submerged. Any change in FRC between pre- and post-treatment was directly reflected by underwater weight. Durnin and Satwanti assessed RV immediately after the underwater weight while the subject was submerged. However, the food and drink caused an unexplained decrease in RV; i.e. the subjects could exhale more after the meal. These changes in RV, if not reflected in underwater weight, could have confounded their post-test $\%$ fat measurements.

The unexpected inefficacy of the gas-producing Bean meal in the present study may be the result of opposing effects. The weight and density of this meal would tend to increase body density. It also produced the greatest gastrointestinal gas (Levitt and Bond, 1970), a trait which would decrease density. It seems plausible that these effects offset each other. 
The results of this study indicate that dietary preparation can influence assessment of percentage body fat by hydrostatic weighing. The length of fast necessary for accurate and reliable hydrostatic weighing is yet undetermined.

\section{ACKNOWLEDGEMENTS}

This research was supported in part by Rax and Taco Johns restaurants. The authors thank Dr. John A. Roberts for his review of the manuscript and helpful suggestions.

\section{References}

Bedell, G. N., Marshall, R., DuBois, A. B. and Harris, J. H., 1956 “Measuremen of the volume of gas in the gastro-intestinal tract. Values in normal subjects and ambulatory patients". Journal of Clinical Investigation 35: 336-345.

Durnin, J. V and Satwanti, 1982 "Variations in the assessment of the fat content of the human body due to experimental technique in measuring body density". Annals of Human Biology 9: 221-225.
Durnin, J. V. and Taylor, A., 1960 "Replicability of measurements of density of the human body as determined by underwater weighing". Journal of Applied Physiology 15: 142-144.

Girandola, R. N., Wiswell, R. A. and Romero, G., 1977 "Body composition changes resulting from fluid ingestion and dehydration". Research Quarterly 48: 299-303.

Levitt, M. D. and Bond, J. H., 1970 "Volume, composition and source of intestinal gas". Gastroenterology 59: 921-929.

Robertson, C. H., Engle, C. M. and Bradley, M. E., 1978 "Lung volumes in man immersed to the neck: dilution and plethysmographic techniques". Journal of Applied Physiology 44: 679-682.

Thomas, T. R. and Etheridge, G. L., 1980 "Hydrostatic weighing at residual volume and functional residual capacity". Journal of Applied Physiology 49: 157-159.

Thomas, T. R., Etheridge, G. L., Londeree, B. R. and Shannon, W., 1979 "Prolonged exercise and changes in per cent fat determinations by hydrostatic weighing and scintillation counting". Research Quarterly 50: 709-714.

Timson, B. F. and Coffman, J. L., 1984 "Body composition by hydrostatic weighing at total lung capacity and residual volume". Medicine and Science in Sports and Exercise 16: 411-414.

Wilmore, J. H., Davis, J. A., O'Brien, R. S., Vodak, P. A., Walder, G. R. and Amsterdam, E. A., 1980 "Physiological alterations consequent to 20-week conditioning programs of bicycling, tennis, and jogging". Medicine and Science in Sports and Exercise 12: 1-8.

\section{BOOK REVIEW}

Title: DIAGNOSTIC PICTURE TESTS IN INJURY IN SPORT

Author: J. G. P. Williams

Publisher:

$$
\text { Wolfe Medical Publications, London } 1988
$$

Price: $\mathrm{f6.50} \quad 128$ pages Soft cover 200 questions with answers

ISBN 0723409255

Wolfe's Diagnostic Tests are already quite well-known in several branches of medicine, especially in those branches such as orthopaedics and rheumatology where the diseases or injuries lend themselves to colour photographs or X-rays. This selftesting book falls well into this category. My first impression was that the illustrations would merely be taken from the author's previous Colour Atlas of Injury in Sport or other publications, but I was surprised to find that most of the pictures were new to me. Another early impression was the completely random arrangement of the conditions, anatomically and pathologically, which would make it difficult to search for an illustration of any particular lesion, but then, it is not a text-book to be used for reference, but what it sets out to be, 200 pictures with brief clinical notes to test the knowledge and observation of the reader, as in the picture quizzes in some of the medical newspapers, and to let him check the answers immediately. The random order cannot be regarded as a weakness, but rather it simulates the random order in which patients present themselves in a clinic or general practice consulting room or even a changing room. A most important point brought out is that pathology in a sportsman may not be due to sport, but to totally unrelated conditions such as malignant or non-malignant tumours, congenital malformations or accessory bones that imitate trauma unless the X-rays are studied carefully, and if possible compared with films from the opposite side of the body.

Most of the illustrations are clear, but sometimes minor colour changes are difficult to detect, and several X-rays difficult to interpret in the small size to which they have had to be reduced. In clinical practice, however, some X-rays ARE very difficult to interpret and such conditions as stress fractures are easily missed on first presentation of symptoms. This is not a sort of clinical game of 'Trivial Pursuits', though it could be used in a small group of students, doctors or physiotherapists after lectures during a sports medicine course. At the price of $\mathrm{f} 6.50$ it might be worth course organisers laying in a small stock to test a few of their pupils at a time.

Henry E. Robson 